\title{
Treatment needs, diagnoses and use of services for acutely admitted psychiatric patients in northwest Russia and northern Norway
}

\author{
Knut W Sørgaard ${ }^{1,2^{*}}$, Grigory Rezvy ${ }^{1,2}$, Anatoly Bugdanov ${ }^{3,4}$, Tore Sørlie ${ }^{2}$ and Trond Bratlid ${ }^{2}$
}

\begin{abstract}
Background: We compared demography, diagnoses and clinical needs in acutely admitted psychiatric hospital patients in northwest Russia and northern Norway.

Method: All acutely admitted psychiatric patients in 1 psychiatric hospital in north-west Russia and 2 in northern Norway were in a three months period assessed with HoNOS and a Norwegian form developed to study acute psychiatric services (MAP). Data from a total of 841 patients were analysed (377 Norwegian, 464 Russian) with univariate and multivariate statistics.

Results: Russian patients were more often males who had paid work. 2/3 were diagnosed with alcohol and organic disorders, and $70 \%$ reported problems related to sleep. Depression was widespread, as were problems associated with occupation. Many more Norwegian patients were on various forms of social security and lived in community supported homes. They had a clinical profile of affective disorders, use of drugs, suicidality and problems with activities involved of daily life. Slightly more Norwegian patients were involuntary admitted.

Conclusion: Acutely admitted psychiatric patients in North West Russia and Northern Norwegian showed different clinical profiles: alcohol, depression and organic disorders characterised Russian patients, affective disorders, suicidality and use of drugs characterised the Norwegians. Whereas Norwegian patients are mainly referred from GPs the Russians come via 1.line psychiatric services ("dispensaries"). Average length of stay for Russian patients was 2.5 times longer than that of the Norwegian.
\end{abstract}

Keywords: Russian psychiatry, Acute psychiatry, Inpatient treatment, Comparative studies

\section{Background}

Cultural, political and economic values strongly influence how human services systems are organized and how they operate. In this paper we compare acutely admitted psychiatric patients in north-west Russia and in northern Norway with regard to demography, admission characteristics and treatment needs. Northern Norway and north-west Russia are sub-arctic and mainly rural areas with some scattered urban or semi-urban centres. Differences exist with regards to demography, history, culture and economy. Whereas Norway has profited from decades of political stability, is among the most affluent

\footnotetext{
* Correspondence: kso@nlsh.no

'Nordland Hospital Trust, Bodø 8092, Norway

2Department of Clinical Medicine, University of Tromsø, Tromsø 9001 Norway

Full list of author information is available at the end of the article
}

countries in the world and exemplifies the Scandinavian well fare model, Russia has suffered from decades of authoritarian political regimes, and later - as other East European countries - has endured considerable social changes that has led to what has been called a "community syndrome": increasing death rates, more depression, addiction, cerebrovascular and cardiovascular problems, and destructive and self destructive behaviour [1-5]. It is documented that social deprivation, lack of stable housing and community based services contribute to increased use of acute psychiatric services [6,7]. In Russia [6], as in Western Europe [7,8], the acute ward may come under pressure due to hospital downsizing, a rising number of admissions, staffing problems and patients with complex needs and challenging behaviour $[7,9]$. There have been few international comparative 
studies on acute psychiatric services [10] and Eastern Europe is seldom included [11]. The WHO 17-countries study of use of mental health services concluded that the effects of different mental health policies, delivery systems, and financing "is essentially unknown" and that detailed data relevant to these topics should be collected [12]. Russian psychiatry is not well known in Western Europe. Psychiatric care in Northern Norway and the Arkhangelsk region has previously been systematically compared at a treatment system level [13] by our group. The present study is intended to supplement this by adding clinical and demographic data of the users of acute psychiatric services in north west Russia (the Arkhangelsk region) and northern Norway.

We expected to find: (a) Alcohol/drug and organic problems would be more common among Russian patients, whereas among the Norwegian patients affective problems and problems related to suicidality would dominate. (b) Due to more deprived social and economic conditions, serious mental problems (as measured by HoNOS) would be more common among the Russian patients. (c) A less developed social security system in Russian would cause Russian patients to stay in ordinary employment whereas more Norwegian patients would live on social security.

\section{The context of the study}

Confinement, a strong belief in science and close contacts with the political system are characteristics of psychiatry in the Soviet period [14]. Since the beginning of the 1990s, there has been a gradual acceptance of the bio-psycho-social model, diagnostic and clinical guidelines more in accordance with European standards, reduction in the number of beds, and multiprofessional teambuilding. The collapse of the economy in the 1990s reduced governmental financing and caused difficulties for patients and professionals [14]. New psychotropics are available, but their uses depend on the region's funding [15]. There is no national health insurance comparable to those in Western Europe [15]. Russia established a national law on psychiatry in 1992 [14] that is comparable to the Norwegian one [13] and the services have gradually developed in the direction of European standards: decentralising, strengthening of social psychiatric approaches, incorporating new treatment methods, and integrating psychiatry and somatic medicine. The primary care and the social services are still peripheral in the treatment of people with mental disorders [16]. Bed capacities are to a large extent centralised to hospitals with more than 1000 beds, and in 2006 the average length of stay for all patients was 77.4 days [17]. Outpatient services, mainly "dispensaries" staffed with psychiatrists are well developed in urban [13] and psychiatric "psychotherapy-cabinets", are established in rural areas [17]. Health care development is increasingly based on epidemiological studies [13].
Both Arkhangelsk County and Northern Norway are mainly rural areas with a low population density, particularly Arkhangelsk with its 1.3 mil inhabitants living in an area covering 587000 square kilometres. About 400, 000 lives in the city of Arkhangelsk and ca. 200, 000 in Severodvinsk. In Northern Norway 470, 000 inhabitants live in an area of 113000 square kilometres - one third Norway's territory. The number of emergency beds per 100000 inhabitants in Arkhangelsk is about the same as in northern Norway [13]. The Arkhangelsk psychiatric hospital included in the present study, has about 900 beds, nine acute wards with 50-70 patients each and low staffing, approximately about $2-4$ nurses and 4 nurse auxiliaries at each shift. In the last ten years, there has been systematic staff training in milieu therapy and multiprofessional cooperation in selected units $[18,19]$. A system of crises services has been established [17]. In Northern Norway, the principles of 'regionalisation' and 'sectorisation' predated a network of 14 community mental health centres (DPS District Psychiatric Centres) that together with 2 downsized mental hospitals are the main components of the mental health system. There are 247 beds in the two hospitals, 69 of them in acute wards. The number of beds in a typical acute ward is 10-12, the staff consists of about 25 nurses/nurse auxiliaries in addition to psychologists (1-2), psychiatrists (1-2) and social workers (1). Each shift (daytime) may consist of 6-8 nurses/nurse auxillaries in addition to available psychologist, psychiatrist and social worker in wards with $10-14$ beds. The standard procedure is short hospital stays and a rapid return to the patients' homes in close collaboration with the primary health services in the patients' home municipalities. Patients in need of specialized psychiatric follow-up are referred to the DPSs. All DPSs have mobile acute teams [20]. In addition, the municipalities operate a differentiated network of psychiatry-related services (GPs, social services, psychiatric nurses and psychiatric day care centres). The degree of decentralization in the mental health services is much higher in Northern Norway than in Russia [13] and the GPs have a more central role in the treatment of mental disorders.

\section{Methods}

This study was an observation study with demographic data collected at admission, clinical information (symptoms, treatment-relevant information etc.) recorded at admission and at discharge. The data collection period was 3 months. A total of 983 admissions were included, but due to a number of readmissions (105 in Norway and 55 in Russia) that might result in clustered data, the analyses are based on the participants' first admission in the study period. A total of 841 admissions were analysed (377 Norwegian, 464 Russia). The patients' therapists (psychiatrists or psychologists) were responsible for the 
data collection which took place in connection with ordinary clinical interviews. A form with 67 variables was filled out for each admission by the patients' therapists in collaboration with other staff who knew the patient. The form was originally developed for use in the national Norwegian acute ward study - the MAP study [18] and has 8 sections and 67 variables: (A) referral and admission, (B) demographic data about the patient, $(\mathrm{C})$ service received before the admission, (D) assessments made at admission, (E) systematic assessment and treatment made during the stay, (F) coordination and collaboration, (G) evaluation at discharge, and (I) data about the discharge. The HoNOS [19-21] is integrated in it. HoNOS is generally used for describing the pathology and clinical (8 items) and social needs ( 4 items) across 12 broad mental-health related dimensions [22-24]. It consists of 12 5-point scales from 0 (no problem) to 4 (severe/very severe problem). It was developed at the UK Royal College of psychiatrists as a routine outcome measure in mental health services. HoNOS was recorded at admission and at discharge.

In the present study, the forms and training material (case vignettes) were translated from Norwegian/English into Russian by one of the authors (GR), back translations were performed and necessary adjustments made. Therapists responsible for the HoNOS completed a one-week training course. The training started with a thorough presentation of the instruments, a number of case vignettes were rated, the scores were compared consecutively and discussed in the groups with the instructors present. To reduce ambiguity in the variable interpretation, written definitional criteria were available for the therapists. The HoNOS instructors could also easily be reached (emailing, telephone). The ethical committees in Northern Norway and at the Medical University in Arkangelsk approved the study, and also accepted that patients unable to give informed consent were included. The reason was that excluding patients would make the study unrepresentative for the total group of acute ward patients. ICD-10 diagnoses were used [25].

\section{Statistics}

Frequency analyses, chi-square, T-tests on the demographic- and admission-related data, and standard binary logistic regression were used to characterise the main differences between patients in the two systems with country as the dependent variable $(0=$ Norway, $1=$ Russia $)$. Logistic regression was performed due to it's potential for predicting which of two categories (e.g. Russian vs Norwegian hospitals) a person was likely to be admitted to. Potential explanatory variables were chosen with a significance value of .25 on univariate analyses as criteria for inclusion [26]. Variables that were not mulitvariately significant $(\mathrm{p} \leq .05)$ on the Wald statistics in the first step of the analyses, were removed and subsequent analyses run without them [27]. Based on the $\mathrm{p} \leq .001$ criterion for Mahalanobis distance, which is used to identify particularly influential cases, outliers were removed. Depending on the choice of strategies, regression analyses may give some more or less related models. The final choice of model was made from the principle of parsimony [26] which emphasizes that a simple model is better than a more complex one. Initially, a demographic model was tested out and subsequently clinical variables were added. The forced entry procedure was used.

\section{Results}

Russian patients (Tables 1 and 2) were older, more often males, fewer lived alone, and they more often lived in houses/flats. More Norwegians had institutional care (lived in community based care homes), and were on social securities. Russian patients were referred from dispensaries and medical emergency services, most Norwegians from GPs or medical emergency services. Slightly more Russians were voluntary admitted. Compulsory observation is a specific Norwegians alternative: patients can be involuntary admitted for observation for a maximum of 20 days. They cannot be medicated against their will, but be transferred to ordinary compulsory admission. The Russian patients were diagnosed with mainly alcohol/drug and organic disorders, whereas affective disorders, psychosis and "other disorders" were common among the Norwegians. HoNOS (Table 3) showed that high scores on Other mental or behavioural problems, Problems with relationships and Depressed moods characterised both groups. The Russian profile was problem drinking and drug-taking, problems with occupation and/activities, and with living conditions and hallucinations/delusions. The Norwegian was characterized by non-accidental self-injury, problems of activities of daily living, overactive/aggressive/disruptive behaviour and cognitive problems. The most common "Other mental problems" were (Norwegian patients): anxiety (1/3) and sleep disorders (1/4), and (Russians patients) sleep disorders $(70 \%)$ (Chi square 144.1, p = .000). Logistic regression (Table 4). Russian patients were more often living in flats/houses, together with parents, more often had work related income (compared to social security), were marginally older and more often of male sex. Percentage of of correct classification was 56.7; Hosmer/Lemeshow Chi sq. 23.04, $\mathrm{p}=.003$; Nagelknerk $\mathrm{R}^{2} .14$. Adding clinical variables, a more distinct set of variables with stronger statistical values characterised the Russian patients than the Norwegians: organic disorders, alcohol/drug related problems and source of income, older age, living in houses/flats (compared to community based care), more problems related to work and activities, and from depression. Affective disorders, suicidality at admission and problems related to activities of daily living characterised the Norwegian patients. Percentage of correct classification 
Table 1 Demographic characteristics of the Norwegian and Russian patients

\begin{tabular}{|c|c|c|c|c|}
\hline Variable & & Norway & Russia & $\mathbf{P}$ \\
\hline Age & & 39.9 (s.d. 14.6) & 44.1 (s.d.14.3) & $p=.000 ; 95 \% \mathrm{Cl}:-6.20 / 2.50$ \\
\hline Sex & Female & $171(48.4 \%)$ & $188(38.8 \%)$ & Chi sq 7.62, $p=.006$ \\
\hline \multirow[t]{2}{*}{ Marital status } & Married, cohab. & $60(17.1 \%)$ & $136(29.4 \%)$ & Chi sq $76.70, p=000$ \\
\hline & Living alone & $271(58.9 \%)$ & $136(27.4 \%)$ & Chi sq $184.85 p=.000$ \\
\hline \multirow[t]{2}{*}{ Children } & Have children < 18yrs) & $86(24.3 \%)$ & $92(19.8 \%)$ & NS \\
\hline & No of children & .48 & .27 & T-test $51.56 p=.001$ \\
\hline \multirow[t]{5}{*}{ Housing/dwelling } & House/flat & $221(62.4 \%)$ & 367 (79.1\%) & Chi sq $59.42 p=.000$ \\
\hline & Institution/care unit & $56(15.8 \%)$ & $9(1.9 \%)$ & \\
\hline & Parents/others & $43(12.1 \%)$ & $65(13.3 \%)$ & \\
\hline & Homeless & 17 (3.5\%) & 17 (3.4\%) & \\
\hline & Other & $33(6.7 \%)$ & $13(2.5 \%)$ & \\
\hline \multirow[t]{5}{*}{ Income } & Paid work & $30(8.5 \%)$ & $115(24.8 \%)$ & \\
\hline & Disability pension & $160(45.2 \%)$ & $142(30.6 \%)$ & \\
\hline & Other social security & $93(26.3 \%)$ & $4(.9 \%)$ & Chi sq 215.08, $p=.000$ \\
\hline & Old age pension & $22(6.2 \%)$ & $59(12.7 \%)$ & \\
\hline & Other & $46(13.0 \%)$ & $61(13.1 \%)$ & \\
\hline
\end{tabular}

T-tests, chi square. $\mathrm{N}=841$.

Table 2 Formalities of referral and admission, diagnosis and HoNOS-ratings

\begin{tabular}{|c|c|c|c|c|}
\hline & Variable & Norway & Russia & $\mathbf{P}$ \\
\hline Previous psychiatric treatment & Yes & $298(83.4 \%)$ & $336(72.4 \%)$ & Pearson Chi square $14.02 p=.001$ \\
\hline \multirow[t]{6}{*}{ Referred from } & Patient him/herself & $9(2.5 \%)$ & $35(7.5 \%)$ & Pearson Chi square $314.2, p=.000$ \\
\hline & GP & 99 (28.0\%) & $5(1.1 \%)$ & \\
\hline & Casualty clinic & $142(40.1 \%)$ & $156(33.6 \%)$ & \\
\hline & Psychiatric outpat. units & $12(3.4 \%)$ & $220(47.4 \%)$ & \\
\hline & Other psychiatric services & $44(12.4 \%)$ & $3(0.7 \%)$ & \\
\hline & Other & $48(13.6 \%)$ & 45 (9.7\%\%) & \\
\hline \multirow[t]{4}{*}{ Juridical basis for admission } & Voluntary admissions & $214(60.5 \%)$ & $304(66.2 \%)$ & Pearson Chi square 111.02, $p=.000$ \\
\hline & Compulsory observation & $68(19.2 \%)$ & $0(0 \%)$ & \\
\hline & Compulsory admissions & $68(19.2 \%)$ & $157(33.8 \%)$ & \\
\hline & Other & $6(1.5 \%)$ & $0(0 \%)$ & \\
\hline The patient wanted to be admitted & & $209(59.4 \%)$ & $332(69.4 \%)$ & Pearson Chi square $17.4 p=.000$ \\
\hline Length of stay (days) & & $11.1(14.1)$ & $26.7(19.0)$ & $F 93.52 p=.000$ \\
\hline \multirow[t]{5}{*}{ Diagnosis ICD 10} & Organic & $10(2.8 \%)$ & $78(16.8 \%)$ & Chi sq $40.91, p=.000$ \\
\hline & Alcohol/drugs & $29(8.2 \%)$ & $217(46.8 \%)$ & Chi sq 142.09, $p=.000$ \\
\hline & Affective disorders & 97 (27.4\%) & $17(3.7 \%)$ & Chi sq $94.33, p=.000$ \\
\hline & Psychosis & $120(33.9 \%)$ & 109 (23.5\%) & Chi sq $10.79, p=.001$ \\
\hline & Other diagnosis & $98(27.2 \%)$ & $43(9.3 \%)$ & Chi sq 49.94, $p=.000$ \\
\hline HoNOS & Total scores at admission & $14.41(5.87)$ & $15.38(5.02)$ & $F 7.82, P<.001$ \\
\hline "Improvement" (HoNOS) & Difference in vs out rating of total scores & 5.50 & 8.20 & $F 39.3, p<.000$ \\
\hline \multirow[t]{2}{*}{ GAF } & Gaf F admission & $36.2(12.6)$ & $38.9(12.2)$ & $F 1.99, p=.003$ \\
\hline & Gaf $\mathrm{S}$ admission & $39.3(12.3)$ & $40.2(12.7)$ & NS \\
\hline
\end{tabular}

Chi-square and T-tests. 
Table 3 HoNOS ratings Russian and Norwegian patients

\begin{tabular}{lllll}
\hline & Russia & & & Norway \\
\cline { 2 - 5 } HoNOS & Nil to minor & Mild to severe & Nil to minor & Mild to severe \\
\hline HoNOS 1 (Overactive, aggressive, disruptive) & $322(69.5 \%)$ & $141(30.5 \%)$ & $231(61.3 \%)$ & $146(39.7 \%)$ \\
HoNOS 2 (Non-accidental self-injury) & $428(92.7 \%)$ & $35(7.3 \%)$ & $261(69.8 \%)$ & $115(30.2 \%)$ \\
HoNOS 3 (Problem drinking, drug-taking) & $213(46.4 \%)$ & $246(53.6 \%)$ & $271(72.8 \%)$ & $101(27.2 \%)$ \\
HoNOS 4(Cognitive problems) & $386(83.7 \%)$ & $75(16.3 \%)$ & $270(74.0 \%)$ & $119(26.0 \%)$ \\
HoNOS 5 (Physical illness, disability) & $348(75.2 \%)$ & $121(24.8 \%)$ & $288(76.6 \%)$ & $109(24.4 \%)$ \\
HoNOS 6 (Hallucinations, delusions) & $179(38.7 \%)$ & $304(61.3 \%)$ & $175(47.8 \%)$ & $191(52.2 \%)$ \\
HoNOS 7 (Depressed moods) & $251(54.2 \%)$ & $224(45.8 \%)$ & $180(49.0 \%)$ & $187(51.0 \%)$ \\
HoNOS 8 (Other mental or behavioural problems) & $139(34.6 \%)$ & $300(65.4 \%)$ & $24.7 \%)$ & $274(75.3 \%)$ \\
HoNOS 9 (Problems with relationships) & $180(39.1 \%)$ & $299(60.9 \%)$ & $138(37.1 \%)$ & $234(62.9 \%)$ \\
HoNOS 10 (Problems with activities of daily living) & $359(77.7 \%)$ & $103(22.3 \%)$ & $201(54.9 \%)$ & $215(45.1 \%)$ \\
HoNOS 11 (Problems with living conditions) & $294(64.1 \%)$ & $174(35.9 \%)$ & $147(83.4 \%)$ & $76(16.6 \%)$ \\
HoNOS 12 (Problems with occupation/activities) & $168(36.8 \%)$ & $291(63.2 \%)$ & $247(68.8 \%)$ & $112(31.2 \%)$ \\
\hline
\end{tabular}

increased to 83.6. Hosmer/Lemeshow Chi sq. 13.08, $\mathrm{p}=.09$; Nagelknerk $\mathrm{R}^{2} .84$.

\section{Discussion}

(i) Use of services

80 of the Russian patients were referred from dispenseries (psychiatric outpatient clinics/ psychiatric "psychotherapy- cabinets") and medical emergency services, in Norway $70 \%$ came from GPs and medical emergencies. This reflects a structural difference in the mental health services between the two countries: Russia has a network of 1.line psychiatric specialist services where Norway - and most Western countries - uses GPs. The use of civil commitment in Norwegian psychiatry is among the highest in

Table 4 Direct logistic regression analysis of patient nationality as a function of demographic variables

\begin{tabular}{|c|c|c|c|c|c|}
\hline \multirow[t]{2}{*}{ Variables } & \multirow[t]{2}{*}{ B } & \multirow[t]{2}{*}{ Wald } & \multirow[t]{2}{*}{ Odds Ratio } & \multicolumn{2}{|c|}{ 95\% C.I for $\operatorname{Exp}(B)$} \\
\hline & & & & Lower & Upper \\
\hline \multicolumn{6}{|l|}{ Demographic variables } \\
\hline Age (MAP) & .020 & 14.91 & 1.02 & 1.01 & 1.03 \\
\hline Sex (MAP) & -.52 & 11.81 & .59 & .44 & .80 \\
\hline Income from work (MAP) & 1.29 & 42.07 & 3.64 & 2.32 & 5.68 \\
\hline Living in own flat/house (vs by parents, institution etc) (MAP) & .68 & 16.46 & 1.98 & 1.43 & 2.75 \\
\hline Total model: & \multicolumn{5}{|c|}{$\begin{array}{l}\text { Correct classifications: } 56.7 \% \text {; Hosmer/Lemeshow Chi sq. 23.04, } \mathrm{p}=.003 ; \\
\text { Nagelknerk } \mathrm{R}^{2} .14\end{array}$} \\
\hline \multicolumn{6}{|l|}{ With clinical variables added } \\
\hline Income from work (MAP) & 1.44 & 16.60 & 4.23 & 2.11 & 8.46 \\
\hline Living in own flat/house (MAP) & .76 & 7.44 & 2.15 & 1.24 & 3.72 \\
\hline Depression (HoNOS) & .28 & 6.64 & 1.33 & 1.07 & 1.64 \\
\hline Problems related to activities of daily life (HoNOS) & -.82 & 40.66 & .44 & .34 & .56 \\
\hline Problems related to occupation and activities (HoNOS) & 1.07 & 92.73 & 2.91 & 2.34 & 3.61 \\
\hline Organic disorders (ICD-10) & 2.32 & 25.91 & 10.21 & 4.17 & 24.97 \\
\hline Alcohol/drugs (ICD-10) & 2.47 & 52.39 & 11.81 & 6.05 & 23.05 \\
\hline Affective disorders (ICD-10) & -1.72 & 21.33 & .18 & .09 & .37 \\
\hline Use of drugs & -1.60 & 46.87 & .20 & .13 & .32 \\
\hline Risk of Suicidality at admission (MAP) & -.58 & 37.19 & .56 & .46 & .67 \\
\hline
\end{tabular}

Norway $=0$, Russia $=1$. Only significant variables are shown. 
Europe [28], and more Norwegian patients than Russians were committed. Norwegian patients had also more often received psychiatric inpatient treatment in the last 12 months before admission, whereas the proportion that had used outpatient service was almost identical. The length of stay for the Russian patients was about $2 \frac{1}{2}$ times longer than for the Norwegians. Thus, the revolving door profile was more pronounced in the Norwegian system. In addition to a later entry into the "deinstitutionalizationage", probable explanations for the longer stays and slower admission/readmission cycles in Russia may be their relative lack of outpatient services, e.g. community teams, interagency collaboration [16] and aftercare services in the peripheral areas [29]. Due to this, hospital psychiatrists often try to complete the treatment of the patients before the discharge. This assumption is strengthened by Russian patients more often being considered to be symptom free in the periods between admissions and that fewer were considered as suffering from "deterioration of an existing illness". This may reflect cultural differences in how "worsening vs. improvement" is interpreted, or it may relate to real treatment gains: Russian therapists rated their patients' average improvement (that is: HoNOS in vs HoNOS out) as higher than their Norwegian colleagues. However, the assumption of longer hospital stays leading to more clinical improvement is not well supported by previous research [30].

\section{(ii) Demography and clinical needs}

High scores on other mental or behavioural problems, problems with relaionships and depressed moods (all HoNOS) characterised both Russian and Nowegian patients. Diagnostically (ICD-10), more Russians suffered from alchol and/or drug abuse and had organic disorders. In spite of the prevalence of depressed moods (54\%), only 9 Russian patients were diagnosed with affective disorders. On the HoNOS, the specific Russian problem areas were problem drinking and drug-taking, problems with occupation and activities, with living conditions and hallucinations/delusions. Among the Norwegians, the most comon diagnoses were affective disorders, psychosis and "other diagnoses". No-accidental self-injury, activities of daily living, overactive/aggressive/disruptive behaviour and cognitive problems dominated the HoNOS-scores. According to Rezvy et al, compared to Russianpsychiatrists, the diagnostic practice of their Norwegian colleagues may show a tendency to focus on the affective aspects of schizoaffective disorders and overestimate the degree of depression in moderate depressive cases [31]. Nevertheless, based on our data there appear to be mismatch between the HoNOS ratings of depressed moods among Russian patients and the infrequent use of ICD-10's affective disorders. (iii) The multivariate analyses showed the Russian patients to be characterised by organic disorders, alcohol related problems, depression, problems related to activities of daily life, to work and activities. They were more often employed and lived in houses/flats (in contrast to community based care homes). Affective disorders, suicidality at admission, use of drugs and problems related to activities of daily living characterised the Norwegian patients. The problems of alcohol abuse in Russia are well known [32,33] and organic disorders are obvious consequences. High prevalence of depression associated with alcohol and general problems of life style is reported in other studies from Eastern Europe, including Russia [5,34,35]. In the present study, $40.4 \%$ of the Russian patients had serious alcohol problems (continuous use of alcohol, use disturbing other activities, spending much time trying to get it) compared to only $8.3 \%$ of the Norwegians. A national Norwegian 2003 census-day study found that only $10 \%$ of all psychiatric inpatients had alcohol or substance abuse diagnoses [36]. On the other hand, serious use of drugs was more frequent among the Norwegians patients ( $10.1 \%$ vs $1.1 \%)$. Sleep problems accompanies both chronic and acute abstinence and may contribute to further drinking problems among persons with alcohol problems [37]. 70\% of the Russian patients reported sleep problems.

Nock et al [38] found mood disorders to be a common risk factor of suicidality in high-income countries, whereas impulse-control disorders - related to for example alcohol abuse - were more dominant in low-and middle income countries. Suicide rates in Russia are linked to high alcohol-consumption [39]. Affective problems and suicidality were prominent in Norwegian patients, but in spite of widespread problems with drug and alcohol abuse and HoNOS-rated depressed moods, suicidality at admission affected only about $7 \%$ of the Russian patients (compared to $1 / 3$ of the Norwegians). When rated during the stay, $2.7 \%$ of the Russian patients and $15.2 \%$ of the Norwegians had moderate to high suicidal risk. The low frequency of suicide related problems among the Russian patients may lead on to ask about how these problems are conceptualised and assessed in Russian hospitals. Acutely admitted Russian patients with observable alcohol problems are often admitted directly into the "narcological departments" (wards specializing in the treatment of comorbid psychiatric and drug/alcohol disorders) of psychiatric hospitals, which may lead to an underdiagnosing of disorders related to affective problems.

Norwegian patients had an average HoNOS-total at admission of 14.41 points, Russians 15.38. The HoNOSscores from both countries did not differ substantially from what has been found in other inpatient studies [40-46], but due to the structural and demographic differences between the two countries, the difference may seem unexpectedly small. A partly explanation may be different attitudes towards admitting mental problems: In a comparative study, 
Angermeyer et al [10] found that Russian respondents had a stronger tendency to consider mental disorders as selfinflicted. Corresponding guilt and shame may prevent disclosure of mental health problems. There may also have been downward adaption to poorer living conditions among Russian patients.

\section{Employment}

Compared to the Norwegian sample, a greater proportion of the Russian patients were employed ( $25 \%$ vs $8 \%$ ), and far more Norwegian patients ( $71.5 \%$ vs $31.5 \%$ ) were on social security. When we compared the score on the HoNOS-item that measures problems with occupation and daily activities, the difference between those who were employed and those who were not, was much more pronounced among the Russian patients (.95 vs 2.20, $\mathrm{p}=.000, \mathrm{~F}=30.60)$, than among the Norwegians (.47 vs .85, NS). Thus, the bonus of being employed appeared to be much greater for the Russian patients. The probable causes is that the more generous Norwegian social security arrangements make it possible for people without jobs to live an economically decent life, but with problems related to activities of daily living (HoNOS 10) as a consequence. Disability benefit recipiancy has increased in most OECD-countries despite improvement in most health indicators [47], and mental disorders account for up to one-third of the total disability pensions with depression is the major cause [48,49]. In Norway the figure is $29.7 \%$ and about 12 times more is spent on disability-related programs than on unemployment [47]. In Russia, invalidity due to psychiatric disorders is also increasing (with $36 \%$ from 1990 to 2000 [4]) and disabled status and disability pensions are also here to some extent used as survival strategies [50].

\section{Critical comments}

The strength of the study was that (1) most of the acute wards in the relevant areas participated (Norway 4 out of 5, Russia 100\%). (2) All committed patients took part in the study. (3) The clinicians who did the ratings were systematically trained in the use of the forms and instruments. (4) Written instructions, scorings criteria and support from the study group were easily available (local researchers, telephone). (5) In all the phases of the project, there was close contact between the Russian and the Norwegian study groups. Weaknesses were: (i) The differences in the training of professionals, and the organisation and capacity of the mental health services between Russia and Norway, may have effected the ratings of social and clinical problems [51]. (ii) Due to national adaptions to for example objective living conditions, some HoNOScriterias may have been used differently. (iii) Although forward and back translations were used, linguistic misunderstandings may have occurred. (iv) Only clinical diagnoses were used, and Russian and Norwegians clinicians may use some diagnostic criteria differently [31]. (v) There may have been different thresholds between Russian and Norwegian patients for reporting mental problems [10].

\section{Competing interests}

There are no competing interests in the study.

\section{Authors' contribution}

KWS led the data collection at one of the Norwegian hospitals, did the statistical analyses and wrote the draft of the manuscript. GR led the Russian part of the study, translated the MAP and the HoNOS into Russian, trained the Russian staff, and commented on the manuscript. AB led the data collection in the participating Russian wards, read and commented on the manuscript, TS contributed to the planning of the study and commented on the manuscript, TB led the datacollection at the other Norwegian hospital, read and commented upon the manuscript. All authors read and approved the final manuscript.

\section{Author details}

${ }^{1}$ Nordland Hospital Trust, Bodø 8092, Norway. ${ }^{2}$ Department of Clinical Medicine, University of Tromsø, Tromsø 9001, Norway. ${ }^{3}$ North State Medical University, Arkhangelsk, Russia. ${ }^{4}$ Arkhangelsk Clinical Psychiatric Hospital, Arkhangelsk, Russia.

Received: 10 December 2012 Accepted: 4 January 2013 Published: 14 January 2013

\section{References}

1. Rutz W: A need to rethink social psychiatry in Europe. Lancet 2004, 363(5):1562.

2. Rutz W: Social psychiatry and public mental health: present situation and future objectives. Time for rethinking and renaissance. Acta Psychiatrica Scandinavia 2006, 113(Suppl 429):95-100.

3. WHO: Mental Health in Europe: Country reports from the WHO European Network on Mental Health, Health Documentation Services. Copenhagen: WHO Regional Office for Europe; 2001

4. Poloshij B, Saposhnikova I: Psychiatric reform in Russia. Acta Psychiatrica Scandinavia 2001, 104(suppl 410):56-62.

5. Bobak M, Pikhart H, Pajak A, Kubinova R, Malyutina S, Sebakova H, Topor-Madry R, Nikitin Y, Marmot M: Depressive symptoms in urban population samples in Russia, Poland and the Czech Republik. Br J Psychiatry 2006, 188:359-365.

6. Dmitrieva TB: Social psychiatry as a priority trend in psychiatric science and practice (in Russian). Vestn Ross Akad Med Nauk 2004, 7:11-15.

7. Ford R, Durcan G, Warner L, Hardy P, Muijen M: One day survey by the Mental Health Act Commission of acute adult psychiatric inpatient wards in England and Wales. BMJ 1998, 317:1279-1283.

8. Lelliott P: Acute inpatient psychiatry in England: an old problem and a new priority. Epidemiol Psichiatr Soc 2006, 15(2):91-94.

9. Shepherd G, Beadsmoore A, Moore C, Hardy P, Muijen M: Relation between bed use, social deprivation, and overall bed availability in acute adult psychiatric units, and alterntive residential options: a cross sectional survey, one day census data, and staff interviews. BMC 1997, 314(7076):262-266.

10. Angermeyer MC, Breier $P$, Dietrich S, Kenzine D, Matschinger H: Public attitudes toward psychiatric treatment. An international comparison. Social Psychiatry and Psychiatric Epidemiology 2005, 40(11):855-864.

11. Patel V, Sumathipala GS: International repreentation in psychiatric literature. Br J Psychiatry 2001, 178:406-409.

12. Wang PS, Aguilar-Gaxiola S, Alonso J, Angermeyer M, Borges G, : Use of mental health services for anxiety, mood, and substance disorders in 17 countries in the WHO world mental health surveys. Lancet 2007, 370(9590):841-850.

13. Rezvy G: The Barents Project in Psychiatry. Bodø/Tromsø: University of Tromsø; 2007.

14. Polubinskaya SV: Reform in psychiatry in post-Soviet countries. Acta Psychiatrica Scandinavia 2000, 101:106-108.

15. Füredi J, Mohr P, Swingler D, Bitter I, Gheorghe MD, Hotujac L, Jarema M, Kocmur M, Koychev GI SNM, et al: Psychiatry in selected countries of 
Central and Eastern Europe: an overview of the current situation. Acta Psychiatrica Scandinavia 2006, 114:223-231.

16. Sørlie T, Rezvy G, Høifødt TS, Yashkovich V, Proselkova E: Collaboration in psychiatry between Arkhangelsk and Northern Norway. J Norwegian Med Assoc 2011, 131(16):1568-1570.

17. Gurovich IY: The current status of psychiatric services in Russia: Moving towards community-based psychiatry. Int I Disabil Community Rehabil 2007, 6(2).

18. Ruud T, Gråwe RW, Hatling T, SINTEF: Acute Psychiatric Treatment in Norway results from a multicenter study. (In Norwegian). Trondheim: Sintef Helse; 2006.

19. Wing JK, Beevor AS, Curtis RH, Park SGB, Hadden S, Burns A: Health of the Nation Outcome Scales (HoNOS). Research and development. British J Psychiatry 1998, 172:11-18.

20. Gråwe R, Ruud T: Alternative acute services in mental health services for adults (in Norwegian). J Norwegian Med Assoc 2005, 125(23):3265-3268.

21. Amin S, Singh P, Croudace T, Jones P, Medley I, Harrison G: Evaluating the Health of the Nation Outcome Scales. Reliability and validity in a three yerar follow-up of first-onset psychosis. British J Psychiatry 1999, 174:399-403.

22. Stein GS: Usefulness of the Health of the Nation Outcome Scale. British $J$ Psyciatry 1999, 174:375-377.

23. Orrell M, Yard P, Handysides J, Schapira R: Validity and reliability of the Health of the Nation Outcome Scales in psychiatic patients in the community. British J Psyciatry 1999, 174:409-412.

24. Salvi G, Leese Slade M: Routine use of mental health outcome assessment: choosing the measure. Br J Psychiatry 2005, 186:146-152.

25. : The ICD-10 classification of and behavioural disorders: clinical description and diagnostic guidelines. Geneva: World Health Organization; 1992.

26. Hosmer DW, Lemeshow S: Applied logistic regression. New York: Wiley; 1989

27. Garson GD: PA765 Statnotes: An online textbook. 1999, http://faculty.chass. ncsu.edu/garson/PA765/statnote.htm.

28. Iversen Kl, Høyer G, Sexton HC: Rates for civil commitment to psychiatric hospitals inNorway. Are registry data accurate. Nord J Psychiatry 2009, 63:301-307.

29. Rezvy G, Øiesvold T, Parniakov A, Ponomarev O, Lazurko O, Olstad R: The Barents project in psychiatry: a systematic comparative mental health service study between Northern Norway and Arkhangelsk county. Soc Psychiatry Psychiatr Epidemiol 2007, 42:131-139.

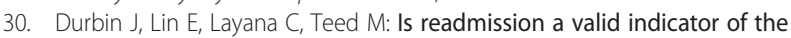
quality of inpatient treatment? J Behav Health Serv \& Res 2007, 34:137-150,

31. Rezvy G, Øiesvold T, Parniakov A, Olstad R: A comparative study of diagnostic practice in psychiatry in Northern Norway and Northwest Russia. Soc Psychiatry Psychiatr Epidemiol 2005, 40:316-323.

32. Nemtsov A: Russia: alcohol yesterday and today. Alcohol 2005, 100(2):146-149.

33. Leon DA P, Saburova L, Tomkins S, Andreev E, Kiryanov N, McKee M, Shkolnikov VM: Hazardous alcohol drinking and premature mortality in Russia: a population based case-control study. Lancet 2007, 9578:16-22. June):2001-2009.

34. Leon DA, Saburova L, Tomkins S, Andreev E, Kiryanov N, McKee M Shkolnikov VM: Hazardous alcohol drinking and premature mortality in Russia: a population based case-control study. Lancet 2007, 369(June):2001-2009.

35. Averina M, Nilssen O, Brenn T, Brox J, Arkhipovsky VL, Kalinin AG: Social and lifestyle determinants of depression, anxiety, sleeping disorders and selfevaluated quality of life in Russia. A population-based study in Arkhangelsk. Soc Psychiatry Psychiatr Epidemiol 2005, 40(7):511-518.

36. Gråwe R, Ruud T: Substance abuse and mental disorders in mental hearlth services for adults (in Norwegian). Trondheim: SINTEF Helse; 2006.

37. Vitiello MV: Sleep, alcohol and alcohol abuse. Addict Biol 1997, 2(2):151-158.

38. Nock MK, Borges G, Bromet EJ, Alonso J, Angermeyer M, Beautrais A, Bruffaerts R, Chiu WT, de Girolamo G, Gluzman S, : Cross-national prevalence and risk factors for suicidal ideation, plans and attempts. Br J Psychiatry 2008, 192:98-105.

39. Nemtsov A: Suicides and alcohol consumptin in Russia, 1965-1999. Drug Alcohol Depend 2003, 71:161-168

40. Bartlett C, Evans M, Holloway J, O'Connor S, Harrison G: Markers of inapproproiate placement in acute psychiatric inpatient care: a five hospital study. Soc Psychiatry Psychiatr Epidemiol 1999, 34:367-375.
41. Bech P, Bille J, Tschütze T, Søndergaard S, Waarst S, Wiese M: Health of the Nation Outcome Scales (HoNOS): Implementability, subscle structure and responsiveness in the daily psychiatric hospital routine over the first 18 month. Nord J Psychiatry 2003, 57:285-290.

42. McClelland R, Trimble P, Fox M, Stevenson MR, Bell B: Validation of an outcome scale for use in adult psychiatric practice. Quality in Health Care 2000, 9:98-105.

43. Kisley S, Campbell LA, Crossman D, Gleich S, Campbell J: Are Health of the Nation Outcome Scales a valid and practical instrument to measure outcomes in Norht America? A three-side evaluation across Nova Scotia. Community Ment Health J 2007, 43:91-107.

44. Burgess P, Pirkis J, Coombs T: Do adults in contact with Australia's public sector mental health services get better? Australia and New Zealand Health Policy 2006, 3:9.

45. Tulloc A, Khondoker MR, Fearon P, David AS: Associations of homelessnes and residential mobility with length of stay after acute psychiagtric admission. BMC Psychiatry 2012, 12:121.

46. Theodoridou A, Jager M, Ketteler D, Kawohl W, Lauber C, Hoff P: The conurrent validity and sensitivity of change of the German version of the Health of the Nation Outcome Scales in a psychiatric inpatient setting. Psychopathology 2011, 44:391-397.

47. Prinz C, OECD: Disability programs in need of reform, Policy Brief; 2003.

48. Paykel ES: Life events, social support and depression. Acta Psychiatr Scand Supp/ 1994, 377:50-58

49. Paykel ES, Brugha T, Fryers T: Size and burden of depressive disorders in Europe. Eur Neuropsychopharmacol 2004, 15:411-423.

50. Thikonova N: Histories of 19 households. A longitudnal study 1996-2001. In Powerty and social exclusion in the new Russia. Edited by Manning N, Thikonova N. Burlington, US: Ashgate Publ Company; 2004.

51. Andrews GM T: Smart vs dumb treatment: services for mental disorders. Curr Opin Psychiatry 1994, 7:181-185.

doi:10.1186/1752-4458-7-4

Cite this article as: Sørgaard et al:: Treatment needs, diagnoses and use of services for acutely admitted psychiatric patients in northwest Russia and northern Norway. International Journal of Mental Health Systems 2013 7:4.

\section{Submit your next manuscript to BioMed Central and take full advantage of:}

- Convenient online submission

- Thorough peer review

- No space constraints or color figure charges

- Immediate publication on acceptance

- Inclusion in PubMed, CAS, Scopus and Google Scholar

- Research which is freely available for redistribution 